\title{
Satellite Communications for the Nonspecialist
}


Downloaded From: https://www.spiedigitallibrary.org/ebooks/ on 26 Apr 2023

Terms of Use: https://www.spiedigitallibrary.org/terms-of-use 


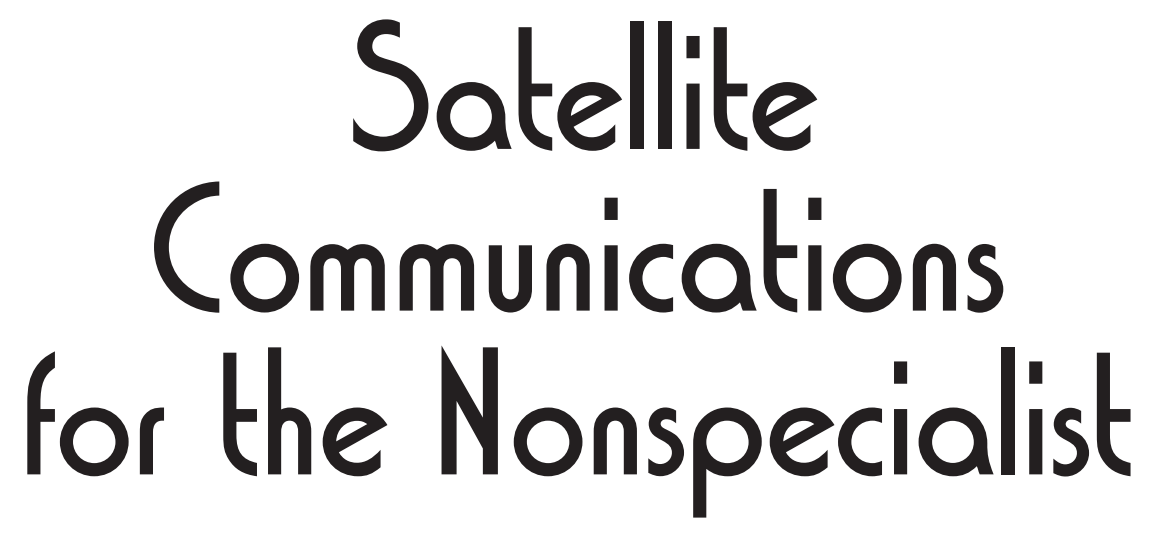

Mark R. Chartrand 
Library of Congress Cataloging-in-Publication Data

Chartrand, Mark R.

Satellite communications for the nonspecialist / Mark R. Chartrand.

p. cm. - (SPIE Press monograph ; PM128)

Includes bibliographical references and index.

ISBN 0-8194-5185-1

1. Artificial satellites in telecommunication-Popular works. I. Title. II. Series.

TK5104.C47 2003

$621.382 ' 5--d c 22$

2003064648

Published by

SPIE-The International Society for Optical Engineering

P.O. Box 10

Bellingham, Washington 98227-0010 USA

Phone: (1) 360.676 .3290

Fax: (1) 360.647.1445

Email: spie@spie.org

Web: www.spie.org

Copyright (C) 2004 Mark R. Chartrand

All rights reserved. No part of this publication may be reproduced or distributed in any form or by any means without written permission of the publisher.

The content of this book reflects the work and thought of the author(s). Every effort has been made to publish reliable and accurate information herein, but the publisher is not responsible for the validity of the information or for any outcomes resulting from reliance thereon.

Printed in the United States of America.

PDF ISBN: 9781510604506

About the cover: The image on the bottom of the front cover shows an "antenna farm" (photograph courtesy of SES Astra). The satellite in the top right is an example of a "Big LEO" satellite that is part of the Iridium constellation (photograph courtesy of Iridium). Between the title and the antenna farm is a glimpse of a regional beam footprint over Europe (photograph courtesy of SES Astra). 


\section{Contents}

Preface

Acknowledgments

xviii

Part 1: Telecommunications and Satellites

Chapter 1 Introduction and Some Historical Background

Chapter 2 The Legal and Regulatory Environment of Telecommunications

2.1 Telecommunications issues 12

2.1.1 Resource allocation $\quad 13$

2.1.2 Money allocation $\quad 14$

2.1.3 The World Trade Organization 16

2.1.4 Other users 16

2.2 Telecommunication statistics 17

2.2.1 What is fair? 17

2.3 Standards and protocols $\quad 19$

2.4 The International Telecommunication Union 20

2.4.1 ITU regions 21

2.5 Other standards and regulatory organizations 24

2.5.1 National regulations and standards 25

2.5.2 Some regulatory jargon 25

2.6 Satellite services and applications 27

2.6.1 Satellite services 28

2.6.1.1 Amsat 29

2.6.2 The major commercial satellite services $\quad 30$

2.6.2.1 Fixed Satellite Service (FSS) 31

2.6.2.2 Broadcast Satellite Service (BSS) 31

2.6.2.3 Mobile Satellite Service (MSS) 32

2.6.2.4 Radiodetermination Satellite System (RDSS) 33

2.6.2.5 Radionavigation Satellite Service (RNSS) 34

2.6.2.6 Inter-Satellite Service (ISS) 34

2.7 Steps to licensing a satellite system 34 
Chapter 3 Satellite Telecommunications: Users, Applications, and

Markets

3.1 Carrying capacity 38

3.2 The place of satellites in telecommunications $\quad 40$

3.2.1 User criteria 40

3.3 Global markets for various applications 43

3.3.1 Television $\quad 43$

3.3.2 Audio broadcast 44

3.3.3 Telephony 45

3.3.4 Data 46

3.4 Satellite services $\quad 47$

$\begin{array}{lll}3.4 .1 & \text { Broadcast video applications } & 47\end{array}$

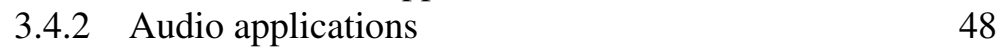

3.4.3 Telephony applications $\quad 49$

3.4.4 Motion picture distribution to cinemas 50

3.4.5 In-flight entertainment and information 51

3.4.6 Telepresence 52

3.4.7 Data distribution and exchange 53

3.4.8 Point-of-sale applications 53

3.4.9 Internet and multimedia via satellite $\quad 54$

3.4.10 Remote monitoring and control 55

3.4.11 Navigation, surveying, and fleet management $\quad 56$

Part 2: Technical Background

Chapter 4 Basic Definitions and Measurements 63

4.1 Communications and networks 63

4.2 Some definitions 66

4.2.1 Channels and circuits 67

4.2.2 Direction of information flow 67

4.2.3 Timeliness 68

4.2.4 Use of transmission facilities 68

$\begin{array}{lll}4.2 .5 & \text { Switching } & 69\end{array}$

4.2.6 Network geometry $\quad 70$

4.3 Measurements: putting a number on it $\quad 72$

4.4 Decibels 73

4.4.1 Ups and downs of power $\quad 76$

$\begin{array}{lll}\text { Chapter } 5 & \text { The Spectrum and Its Uses } & 77\end{array}$

5.1 Properties of waves 77

5.2 The speed of light 78

$\begin{array}{ll}5.3 \text { Inverse square law of radiation } & 79\end{array}$

5.4 Waves, wavelength, and frequency 80

5.5 Radio frequency bands $\quad 82$ 
5.6 Frequency and bandwidth $\quad 85$

5.6.1 More frequency terminology 86

5.6.2 Conversion and intermediate frequencies $\quad 87$

5.7 Other wave properties $\quad 88$

5.7.1 Polarization 88

5.7.2 The Doppler Effect 90

$\begin{array}{lll}\text { Chapter } 6 & \text { Analog and Digital Signals } & 93\end{array}$

6.1 Analog signals 93

6.2 Digital signals 94

6.2.1 Doing our bit for telecommunications 95

6.2.2 Bit players 96

6.3 Bring in the noise 96

6.4 Digital compression 99

Chapter 7 Carrying Information on Waves 103

7.1 Carrying information 103

7.1.1 Coding 104

7.1.2 Pulse-code modulation 106

7.1.3 Encoding video signals 108

7.1.4 Coding for error control 108

7.1.5 Forward error correction 111

7.1.6 Coding for security 112

7.2 Modulation 113

7.2.1 Analog modulation $\quad 115$

7.2.2 Digital modulation 116

7.2.2.1 Energy dispersal 119

7.2.3 Modulation, forward error correction, and throughput 119

7.2.4 Spread spectrum 120

7.3 Multiplexing 120

7.3.1 Space-division multiplexing 122

7.3.2 Frequency-division multiplexing 122

7.3.3 Time-division multiplexing 124

7.3.4 On demand 125

7.4 Networks and protocols 126

7.4.1 Internet via satellite 127

Chapter 8 Signal Flow, Quality, and Noise 129

8.1 Analog signal quality: signal-to-noise ratio 129

8.2 Digital signal quality: bit error rate 130

8.3 Quality during transmission: carrier-to-noise ratio 130

8.4 Improving signal quality 130

8.4.1 Companding analog signals 131

8.4.2 Error correction for digital signals 132 
8.5 The communications circuit and the cocktail circuit 132

8.6 Noise figure and noise temperature 132

8.6.1 Intermodulation noise 135

8.6.2 Satellite-to-satellite interference 135

8.6.3 Terrestrial microwave interference 136

8.7 The limit on capacity 136

8.8 Digital and analog systems' response to noise 137

Part 3: The Space Segment

$\begin{array}{lll}\text { Chapter } 9 & \text { The Space Environment } & 143\end{array}$

9.1 A matter of some gravity 143

9.2 High vacuum 144

9.3 Radiation in space 146

9.3.1 Cosmic rays 147

9.4 Meteor-oids, -ites, and -s 148

$\begin{array}{lll}9.5 & \text { Space debris } & 149\end{array}$

$\begin{array}{lll}\text { Chapter } 10 & \text { Orbits } & 153\end{array}$

10.1 Kepler's Laws 153

10.2 Geosynchronous and geostationary orbits 156

10.2.1 Inclined geosynchronous orbits $\quad 160$

$\begin{array}{ll}10.3 \text { Nongeostationary orbits } & 160\end{array}$

10.3.1 Low orbits 161

10.3.2 "Little" and "big" LEOs 162

10.3.3 "Virtual GEO" orbits 163

10.3.4 Molniya orbits 163

10.4 Geosynchronous transfer orbit 164

Chapter 11 Orbital Slots, Frequencies, Footprints, and Coverage $\quad 169$

$\begin{array}{ll}11.1 \text { Satellite longitude and spacing } & 169\end{array}$

$\begin{array}{ll}11.1 .1 \text { Orbital spacing } & 171\end{array}$

11.2 Once around the Clarke orbit 173

$\begin{array}{lll}11.3 \text { Satellite coverage } & 174\end{array}$

11.3.1 Orbits and groundtracks $\quad 176$

11.4 Satellite orbits and the Sun 176

11.4.1 Eclipses in the Clarke orbit 178

11.4.2 Eclipse protection $\quad 180$

11.4.3 NGSO eclipses 181

11.4.4 Solar outages $\quad 181$

Chapter 12 Out To Launch 185

12.1 The launcher's job 185

12.1.1 A fuel and its rocket are soon parted 187 
12.1.2 Where the rubber meets the road to space

12.1.3 How liquids move your assets

12.1.4 Small thrusters

12.2 The launch vehicle and launch program 189

12.2.1 The launch campaign 192

12.3 Launch vehicles 193

12.4 Launch bases 201

$\begin{array}{lll}\text { Chapter } 13 \text { Satellite Systems and Construction } & \mathbf{2 0 7}\end{array}$

13.1 Satellite manufacturers 207

$\begin{array}{ll}13.2 \text { Major satellite subsystems } & 208\end{array}$

13.2.1 Structural subsystem 211

13.2.2 Antenna system 215

13.2.3 Power generating, storage, and conditioning subsystem 217

13.2.4 Stationkeeping and orientation subsystems 218

13.2.5 Thermal control subsystem 220

13.2.6 Telemetry and command subsystem 220

13.3 Communications payload subsystem 221

13.3.1 Transponder amplifiers 222

13.3.2 Redundancy 223

13.3.3 Transponder characteristics and uses 224

13.3.4 "Bent-pipe" satellites 225

13.3.5 Onboard processing satellites 228

13.3.5.1 Onboard multiplexing 229

13.3.5.2 Intersatellite links 229

Chapter 14 Satellite Operations: Housekeeping and Communications 231

$\begin{array}{lll}14.1 & \text { Satellite operations } & 231\end{array}$

14.1.1 Tracking 231

14.1.2 Telemetry 232

14.1.3 Satellite control 233

14.1.4 Satellite stationkeeping and orientation operations 234

14.1.5 Orientation and pointing 237

14.1.6 Relocation 238

14.2 Satellite lifetime 238

$\begin{array}{ll}14.3 \text { Communication operations } & 240\end{array}$

Part 4: The Ground Segment 241

Chapter 15 Earth Stations: Types, Hardware, and Pointing 243

15.1 Types of earthstations 244

15.1.1 Single-purpose stations $\quad 244$

15.1.2 Gateway stations 247 
15.1.3 Teleports 249

15.2 Environmental effects on antennas 251

15.3 Antenna pointing 252

15.4 Antenna mountings 256

15.4.1 Elevation-azimuth mounts 257

15.4.2 Equatorial mounts 258

Chapter 16 Earthstations: Antenna Properties 261

$\begin{array}{ll}\text { 16.1 Dish antennas } & 261\end{array}$

16.1.1 Feed configuration 263

$\begin{array}{ll}16.2 \text { Horn antennas } & 265\end{array}$

$\begin{array}{ll}16.3 \text { Phased-array antennas } & 265\end{array}$

$\begin{array}{ll}16.4 \text { Yagi antennas } & 265\end{array}$

16.5 Multibeam antennas $\quad 266$

16.6 Nondirectional antennas $\quad 266$

16.7 Dish properties: directionality 267

$\begin{array}{ll}16.8 \text { Dish properties: gain } & 269\end{array}$

16.9 Limits on sidelobe gain 270

Chapter 17 Earthstations: Signal Flow, Electronics, EIRP, and G/T 273

17.1 The length of the link 273

$\begin{array}{ll}17.2 \text { Electronics } & 275\end{array}$

17.2.1 HPAs 275

17.2.2 LNA-B-Cs 276

17.2.3 Receivers 278

17.3 Earthstation functions and signal flow 279

17.3.1 Small receive-only earthstations 279

17.3.2 Two-way earthstations 280

17.3.3 Large earthstations 280

17.4 Other signal processing 283

17.4.1 The echo problem 284

$\begin{array}{ll}17.5 \text { Dish + electronics } & 285\end{array}$

17.5.1 EIRP 285

17.5.2 Figure of merit 287

17.6 Using satellite footprint maps 288

Part 5: The Satellite $\leftrightarrow$ Earth Link $\quad 293$

Chapter 18 Atmospheric Effects on Signals 295

18.1 An optical analogy 295

18.2 Elevation angle and path length 296

$\begin{array}{ll}18.3 \text { Atmospheric effects } & 297\end{array}$

18.3.1 Through a gas darkly 298

18.3.2 Frequency dependence 299

18.3.3 Rain fade and rain fade margins 299 
18.4 Global rain climate models 300

18.4.1 The Crane model 302

18.4.2 The ITU model 303

18.5 Noise from the atmosphere 306

18.6 Polarization effects 306

18.6.1 Rain depolarization 306

18.6.2 Ice depolarization 307

18.6.3 Multipath depolarization 307

$\begin{array}{lll}18.7 \text { Scintillation } & 308\end{array}$

$\begin{array}{lll}18.8 \text { Scattering } & 309\end{array}$

18.9 Improving the quality of a degraded satellite link $\quad 309$

Chapter 19 Putting It All Together: Link Budgets 311

19.1 The link budget $\quad 312$

19.1.1 Turning the formula around 314

19.1.2 Digital signal quality 316

19.2 What's fixed and what's changeable? 316

Chapter 20 Multiple Access: Many Users on One Satellite 319

20.1 Compact system descriptions $\quad 319$

20.2 SDMA: space-division multiple access $\quad 320$

20.3 FDMA: frequency-division multiple access 323

20.3.1 SPADE 326

20.4 TDMA: time-division multiple access $\quad 327$

20.4.1 VSAT as an example of multiple access 329

20.4.2 Aloha 330

20.5 CDMA: code-division multiple access 331

20.6 PCMA: paired-carrier multiple access 333

20.7 Demand assignment 333

20.8 Multiplexing onboard satellite $\quad 334$

20.8.1 Multiple multiplexing $\quad 335$

20.9 Multiple access summary 335

Part 6: Satellite Communications Systems

Chapter 21 Satellite Communications Providers and Competitors 339

21.1 Satellite competitiveness 339

21.2 Satellite's competitors $\quad 342$

21.2.1 Fiber optics $\quad 342$

21.2.2 Stratospheric platforms 342

21.3 Satellite system economics 343

21.3.1 Satellite networks and systems $\quad 344$

21.4 Categorizing satellite systems 344

21.4.1 Treaty-based operators $\quad 345$

21.4.1.1 Arabsat 346 
21.4.1.2 Intersputnik

346

21.4.2 National domestic and regional satellite systems 347

21.4.3 Private satellite operators 347

21.4.3.1 Eutelsat 348

21.4.3.2 Inmarsat $\quad 348$

21.4.3.3 Intelsat $\quad 349$

21.4.3.4 Loral 350

21.4.3.5 New Skies Satellite $\quad 350$

21.4.3.6 PanAmSat 351

21.4.3.7 SES 351

21.5 Using communications via satellite 351

21.5.1 Obtaining space segment 352

21.5.1.1 Transponder brokers 353

21.5.2 Obtaining ground segment services 355

21.5.3 Obtaining TT\&C 355

$\begin{array}{lll}\text { Chapter } 22 & \text { Issues, Trends, and the Future } & \mathbf{3 5 7}\end{array}$

22.1 Rapid changes in the telecommunications industry 357

22.2 Some major telecommunications and satellite issues $\quad 358$

22.2.1 Spectrum availability $\quad 358$

22.2.2 Orbit availability $\quad 359$

22.2.3 Industrial issues $\quad 359$

22.2.4 Launcher and launchpad availability $\quad 360$

22.2.5 Financial capability availability and risk $\quad 360$

22.2.6 Multiple standards 361

22.2.7 Multiple regulatory environments $\quad 361$

22.3 Satellite industry trends 363

22.4 The future of communications via satellite 364

\section{Appendices}

A. Glossary of Common Satellite Telecommunication Terms 367

B. List of Common Acronyms and Abbreviations 393

C. Selected Bibliography for Additional Reading 409

D. Periodicals and Newsletters 413

E. Mathematical Background and Details 415

E.1 Units and measurements 415

E.2 Logarithms and decibels $\quad 416$

E.2.1 Decibels 417

E.3 Bandwidth expressed in decibels 418

E.4 The binary number system 418

E.5 Noise temperature and noise figure 419 
E.6 Shannon's Law of channel capacity 420

E.7 Kepler's Laws of orbits 420

E.8 Orbital parameters $\quad 420$

E.9 Antenna properties 421

E.9.1 Beamwidth 421

E.9.2 Dish gain 422

E.9.3 Antenna gain rule (sidelobe gain rule) 422

E.10 Space loss 423

E.11 Digital link budget 423

E.12 Combining uplink and downlink $C / N$

Index

425 
Downloaded From: https://www.spiedigitallibrary.org/ebooks/ on 26 Apr 2023

Terms of Use: https://www.spiedigitallibrary.org/terms-of-use 


\section{Preface}

The primary purpose of this book, and the introductory seminars out of which it grew, is to explain to nontechnical people the concepts, terminology, buzzwords, and jargon of the commercial satellite communications industry, and to show the interconnections between its various technologies and components. This book attempts to survey the entire commercial satellite telecommunications industry, and to that end discusses everything from decibels; to principles of radio propagation; launch vehicles; link budgets; business, legal, and regulatory issues; and services provided by satellites. The content and presentation have been refined through seminars given for two decades by the author to thousands of businesspeople and hundreds of organizations in public and on-site sessions all over the world. The people who take the seminar, and at whom this book is aimed, come primarily from such occupations as banking and investment, public relations, marketing, writing, insurance, law, and corporate management. These are people who are involved with or interested in the satellite communications industry, but have not had specialized training. In other words, these are the nonspecialists.

Part 1 of this book sets out the historical, business, and regulatory background of the commercial satellite industry. Some examples show how the technology is used to provide specific satellite applications and build markets. Part 2 covers the technical background necessary for understanding the concepts and applications of the entire field of telecommunications. Part 3 continues by explaining the space segment part of the business. Part 4 covers the ground side. Part 5 puts it all together, linking satellites and Earth. Finally, Part 6 contains an overview of the major satellite systems and applications, and a brief discussion of some of the issues and trends affecting the industry.

The chapters of the book contain very little mathematics, just enough to convey the concepts necessary for understanding rather complicated technical concepts. Most of the equations and formulas have been banished to Appendix E, which is provided for those with more mathematical preparation who are interested in the details. For nontechnical readers, the formulas are largely unnecessary for basic understanding of concepts, providing official definitions rather than as something the typical reader is expected to master in detail. The major exceptions to this are a few definitions of terms and the technical climax of the text in Chapter 19 dealing with the all-important topic of link budgets. 
Complex technical concepts are explicated using everyday analogies that allow a nonspecialist to extrapolate from familiar situations to unfamiliar technical applications.

Another objective of the book is to help make palatable the thick, often murky and indigestible alphabet soup of acronyms and abbreviations that are a part of any technical endeavor. Engineers are fine and useful people, but they often forget that not everyone has had the training they have had, and thus they often speak in their own language. (A particular favorite is TDMA, which engineers in the field know to mean "Time-Division Multiple Access" but which many nonengineers consider refers to the "Too Damn Many Acronyms" encountered in the field!) An even more appropriate example is the self-referential TLA, which stands for "ThreeLetter Abbreviation!" The glossary contains a long list of TLAs, FLAs, and so on.

This book is designed to help nonspecialists understand and converse with the technical personnel in the satellite industry, to be able to read and understand the relevant trade journals and exhibits at trade shows, and to help them explain the concepts to their colleagues and customers. (As I jokingly tell my students, by the end of the course they should be able to converse with technical personnel and construct entire sentences containing only jargon and acronyms, and no real English whatsoever!)

Sometimes attendees at the seminars remark at the start that they are interested in a particular aspect of the industry, and not interested in some other topic. By the end of the seminar, they realize that a synoptic view is important. For instance, even if you personally never plan to have to buy a launch vehicle, knowing about launchers is important because what a satellite system operator has to pay for launch partially determines what it has to charge for satellite services.

A very common misconception among nontechnical people who are trying to understand technical issues is that there are generic answers to many technical questions or generic technical solutions to desired services. This desire for simplicity is understandable, but such simplicity is seldom possible. There are always trade-offs, balancing such issues as cost, quality, and speed. For instance, I have had seminar attendees and consulting clients ask such questions as "Which is better, satellites or optical fibers?" or "Which is better, FDMA or TDMA?" or "Which is better, low orbits or high orbits?" The only generic answer to all these questions is "No," because until you know what the detailed requirements of the system are, you cannot specify the technical details. This is another reason that seeing the interconnections of all the parts of the industry is important. You always need to start with the users' requirements and work to find the appropriate technology. This book sets out many of the trade-offs that need to be considered when planning a specific satellite telecommunication service.

A secondary audience is technical people who are entering the commercial satellite communications business for the first time from other fields such as computers, broadcasting, or military satcomms, and for those in the satellite industry who need a refresher to show the applications, relevance, and interconnections of the various 
parts of the industry. Often technical people work in one small specialized area of the industry, and while they know their "trees" well, they have little knowledge of the "forest" of the industry around them. Thus the book includes an overview of the business, technical, and regulatory issues of satellite communications, which often have their own specialized jargon. I have also had many technical people take the seminar in order to learn how to communicate concepts and what they are doing to their less-technical colleagues and customers. More-technical readers will find Appendix E gives them a bit more mathematical depth, but it is not in any way designed as a substitute for more technical engineering references.

As in any introduction, some explanations cannot be as complete or as comprehensive as in more detailed (and highly mathematical) technical references, and some details an engineer might want included have been left out in the interests of simplicity. Nevertheless, it is hoped the examples and analogies will prove useful and instructive, and references are given in the appendices to further information.

Since not every example nor company and its products and services can be included, it is hoped those chosen for illustrative purposes are representative and helpful. The mention of any particular company, product, service, or organization is not intended to be a recommendation of that entity, just as the omission of any particular company, product, or service is not meant as a slight nor negative recommendation, but merely as an indication of availability of appropriate material, or of the reality of constrained space. An extensive appendix points to other, more detailed sources of information. Readers should also search the vast resources of the World Wide Web; some useful addresses are given in the Appendix, with the caveat that websites seem to come and go irregularly.

Further, although this text is intended to be up-to-date, change in telecommunication is rapid, continual, and global. Changes in technology, laws, regulations, politics, corporate structures, and users' needs occur frequently. Sudden events, from launch of a new satellite, to the failure of a satellite, to the purchase of one company by another, can cause instantaneous alterations in the industry. Only periodicals can (attempt to) keep up with this, and you are urged to refer to the magazines and newsletters in Appendix D for the latest information.

Mark R. Chartrand

July 18, 2003 


\section{Acknowledgments}

The production of this book has been the result of almost two decades of wellattended public seminars and on-site seminars to individual firms. I am greatly indebted to the comments and questions from all of the thousands of past attendees who have helped me perfect the order and depth of the explanations, and the usefulness of the analogies. The public seminars are now arranged under the auspices of the Applied Technology Institute.

Particular appreciation is directed to the people who helped get these seminars started, the redoubtable Ellen Hamm Stuhlmann and Mark Kimmel (now both gone on to bigger and better endeavors). Many valuable discussions and ideas have come over the many years from editors and executives, including the redoubtable Scott Chase, Cynthia Boeke, Paul Dykewicz, and David Bross.

The author is also especially grateful for many years of professional and collegial discussions with Richard T. Cassidy, president of the consulting firm Blue Mountain Group and one of the engineers who pioneered the first satellite-distributed radio network. Industry doyen Dr. Joseph N. Pelton supplied many helpful comments. Tim Lamkins at SPIE Press is to be thanked for initiating the publication of this book at the suggestion of one of my erstwhile students, Gunar Fedosejevs. Thanks, too, to F. William Chickering for his helpful comments. Thanks should go also to my partner and my close friends, for putting up with the constraints finishing this book put on my schedule.

In order to illustrate the topics covered herein, I have approached many firms and individuals for assistance. Of particular help were the following, in no particular order: Richard Daniels, AMSAT; Joanne Welsh and Washington Wedderburn at Analytical Graphics; Michelle Lyle and Orly König-Lopez at International Launch Services; Susan Gordon and Max Saffell at Intelsat; Fran Slimmer at Lockheed Martin; Giles Khong at Thales Electrondevices; and Wende Cover at Verestar.

I hope you find this book useful. Thank you. 